\title{
AS AULAS DE EDUCAÇÃO FÍSICA NA VISÃO DE PROFESSORES GENERALISTAS: ANÁLISE SOBRE O ENSINO FUNDAMENTAL \\ ANOS INICIAIS (EFAF)
}

\author{
GENERALIST TEACHERS' PERSPECTIVE ON PHYSICAL \\ EDUCATION CLASSES IN EARLY CHILDHOOD EDUCATION: AN \\ ANALYSIS OF THE ENSINO FUNDAMENTAL ANOS INICIAIS (EFAF)
}

\author{
Ana Carolina Capellini Rigoni ${ }^{1}$ \\ Jederson Garbin Tenório ${ }^{2}$ \\ Lucas de Andrade Carvalho ${ }^{3}$
}

\section{RESUMO}

Foi finalidade desse estudo compreender quais os significados de professoras generalistas sobre o papel da Educação Física na Educação Infantil. Observam-se comportamentos típicos de conflitos entre professoras do primário e os especialistas em Educação Física, decorrentes de questões como, por exemplo, o fato dos alunos, na maioria das vezes, gostarem mais das aulas de Educação Física do que de outras atividades diárias de sala. Foi realizada uma pesquisa qualitativa, com as técnicas de revisão de literatura, observação de campo e a aplicação de entrevistas semiestruturadas para quatro professores generalistas. As professoras afirmaram que a Educação Física é importante e que estas aulas são melhores aproveitadas quando dirigidas por um especialista, embora possuam uma visão funcionalista da disciplina como se fosse um descanso da rotina escolar. A falta do professor de Educação Física pode ser um problema quando elas devem assumir as atividades teóricas com os alunos em sala.

Palavras-chave: Educação Física Escolar; Anos Iniciais; Professores Generalistas.

\section{ABSTRACT}

This study aims to understand generalist teachers' perspectives on the role of Physical Education (P.E.) in Early Childhood Education. We observed typical behaviors in conflicts between Early Childhood Education teachers and P.E. specialists resulting from issues such as that most students enjoy P.E. classes more than other school activities. We conducted qualitative research using literature review together with field observation and

\footnotetext{
1 Atualmente é Professora do Departamento de Ginástica, do Centro de Educação Física e Desportos, da Universidade Federal do Espírito Santo - UFES. Doutora em Educação Física pela Universidade Estadual de Campinas - UNICAMP. Mestra em Educação Física e Sociedade, pela Universidade Estadual de Campinas UNICAMP. e-mail: anacarolinarigoni@yahoo.com.br

2 Mestre em Ciências do Movimento Humano pela FACIS-UNIMEP. Graduado em Educação Física pela Universidade Federal de Mato Grosso. e-mail: jederson.21@ hotmail.com

${ }^{3}$ Mestre em Educação Física pela Universidade Metodista de Piracicaba. Licenciado em Educação Física pela Universidade Estadual de Londrina. e-mail: lucascarvalho2902@gmail.com
} 
performance of semi-structured interviews with four generalist teachers. The teachers affirmed that P.E. is important and better enjoyed when conducted by a specialist, although they have a functionalist view of P.E. as a break from the school routine. The lack of a P.E. teacher may be an issue when the generalist teachers must also conduct the academic activities with the students.

Keywords: Physical Education; Early Childhood Education; Generalist Teachers.

\section{INTRODUÇÃO}

A Lei de Diretrizes e Bases da Educação Nacional (LDB - 9.394/96), estabelecida pelo Ministério da Educação, dispõe que a disciplina de Educação Física é componente curricular obrigatório na Educação Básica. Em 2010, o Conselho Nacional de Educação (CNE) aprovou uma resolução (07) que fixa diretrizes para o Ensino Fundamental (EF). Dentre outras questões, o documento afirma que do $1^{\circ}$ ao $5^{\circ}$ ano, os componentes curriculares Educação Física e Arte poderão ser ministrados pelo professor de referência da turma, também chamado de "professor de sala" ou generalista, ou por professor licenciado no respectivo componente, denominado de especialista. De acordo com este documento, a presença de um professor com licenciatura específica só é obrigatória a partir do $6^{\circ}$ ano do EF.

Muitos foram os debates travados sobre esta resolução e a principal questão que se coloca, desde então (até hoje sem consenso), diz respeito a necessidade ou não do professor especialista nos anos iniciais do $\mathrm{EF}^{4}$. Uma vez que a lei mantém como facultativa a presença do especialista, cada Estado da federação está organizado de maneira distinta. A maioria, das cidades, no entanto, já conta com os professores especialistas em Educação Física e Arte, como é o caso das Escolas Estaduais na cidade de Piracicaba - SP.

Para além do contexto legal, as relações pessoais e profissionais que emergem desta configuração podem ser distintas. Chartier (1998), já falava sobre os problemas que derivariam das diferenças hierárquicas entre a formação e os níveis de professores. A legitimidade dos saberes advogada por cada tipo de professor é, muitas vezes, justificada com

\footnotetext{
${ }^{4}$ Importante ressaltarmos que o artigo supracitado foi alterado duas vezes. A primeira, por conta da lei n. 10.328 (BRASIL, 2001), quando se introduziu a palavra "obrigatório" após a expressão "curricular"; e a segunda vez com a lei n. 10.793 (BRASIL, 2003), ampliando a facultatividade ao ensino noturno relacionado às atividades práticas e não teóricas.
} 


\section{Revista \\ Debates Insubmissos}

bases distintas. Especialistas e generalistas podem construir uma relação de reciprocidade e coletividade ou, ao contrário, uma relação conflituosa, marcada por desacordos e disputas.

Partindo de nossa experiência como especialistas em Educação Física, nos anos iniciais do Ensino Fundamental (EFAI) ${ }^{5}$ e, particularmente nos anos iniciais deste ciclo, percebemos alguns posicionamentos das professoras de sala (generalistas) ${ }^{6}$ que demonstram uma espécie de relação paradoxal com os professores especialistas. Poderíamos pressupor que há, como se costuma dizer, um sentimento de "amor e ódio" destas professoras pelos especialistas em Arte e em Educação Física. Estas tensões podem ser decorrentes de inúmeras questões como, por exemplo, o fato de serem obrigadas por lei a permanecerem junto a turma, mesmo durante as aulas de componentes específicos. Além disso, na maioria das vezes, os alunos podem demonstrar mais afeição aos professores destes componentes específicos do que das outras atividades diárias da escola, entre outras questões.

Esta relação conflituosa fica evidente, também, em situações específicas da rotina escolar, como quando, por exemplo, o especialista falta em seu dia de trabalho, alterando e interferindo na dinâmica cotidiana da professora da sala. A falta da aula do especialista, já programada para aquele dia, significa que a professora de sala não poderá usufruir daquela hora em que seus alunos estariam sob a responsabilidade de outro professor. Esta é uma das questões que mais geram descontentamento entre as professoras generalistas.

Para além destas questões relativas as situações diárias vivenciadas numa escola, uma das principais questões que colocam generalistas e especialistas em conflito diz respeito, como já apontava Sayão (2000), às concepções de trabalho pedagógico destes/as profissionais que, por serem, por vezes, incompatíveis, acabam fragmentando as funções de cada um, produzindo uma ação pedagógica isolada. A falta de compreensão das professoras generalistas sobre o que, de fato, consistem as disciplinas de Educação Física e de Arte é uma realidade no cenário educacional e isto sequer é uma crítica, uma vez que a formação destas

\footnotetext{
5 A Secretaria da Educação do Estado de São Paulo utiliza esta nomenclatura para se referir aos anos da Educação Básicas do $1^{\circ}$ ao $5^{\circ}$ ano.

${ }^{6}$ Sabemos que o número de homens que atuam como professores de sala é muito pequeno. No caso desta pesquisa, todas as professoras entrevistadas são mulheres.
} 
profissionais não as prepara para tal. Da mesma forma, os especialistas, muitas vezes, não conseguem compreender as particularidades de uma turma e as necessidades pedagógicas que deveriam ser tratadas de forma conjunta com a professora de sala.

Mas existem, também, evidências de um sentimento positivo entre estes dois profissionais. Percebemos isso a partir de duas questões: a primeira diz respeito a expressão de felicidade com que as professoras de sala recebem o professor especialista nos horários de suas aulas e a segunda, se refere a uma relação "quase maternal" demonstrada por algumas professoras de sala que, no caso específico desta pesquisa, todas tem bem mais idade, (cerca de vinte a trinta anos) que os professores especialistas. Estas professoras demonstram uma preocupação sincera pelos especialistas quando estes faltam por motivos de saúde e, também, demonstram interesse pelos resultados dos alunos em jogos escolares e outras atividades.

Obviamente, nem todos estes exemplos são frutos de uma relação construída e balizada estritamente por questões profissionais. Muitas vezes, este cuidado das professoras de sala pelos especialistas é fruto de um sentimento de empatia pela pessoa e não necessariamente uma admiração pelo seu trabalho.

Apesar da discussão sobre os papéis do professor generalista e do especialista, de maneira geral, nos interessarem, neste texto focamos especificamente o componente Educação Física. Se, como afirmam Guirra e Prodócimo (2010), na maioria das escolas de educação infantil as professoras generalistas são as responsáveis por realizar o que os autores chamam de "trabalho corporal", no caso do Ensino Fundamental e desta pesquisa, são os professores especialistas que assumem a função de trabalhar com o que preferimos chamar de conteúdos da cultura corporal de movimento.

Diante destas percepções, a questão que se colocava era como as professoras generalistas compreendiam a disciplina de Educação Física no contexto escolar. Diante disto o objetivo desta pesquisa foi compreender quais são, na visão das professoras de sala, os objetivos e o papel principal desta disciplina neste ciclo da Educação Básica. Dito de outro modo, buscamos analisar se estas professoras consideram o componente curricular Educação Física importante e porquê. 


\section{A EDUCAÇÃO FÍSICA NA ESCOLA E SUA ESPECIFICIDADE}

A relação da Educação Física com as demais disciplinas do currículo escolar tem levantado muitos questionamentos, mas independente de qualquer divergência sobre a importância das aulas, já se sabe que ela é parte integrante no currículo escolar, desde a préescola. As aulas de Educação Física são garantidas pela LDB em seu artigo 26 (BRASIL, 1996), que declara:

A educação física, integrada à proposta pedagógica da escola, é componente curricular obrigatório da educação básica, sendo sua prática facultativa ao aluno:

I - que cumpra jornada de trabalho igual ou superior a seis horas;

II - maior que trinta anos;

III- que estiver prestando serviço militar inicial ou que, em situação similar, estiver obrigado á prática da educação física.

Neste sentido, os professores de Educação Física têm idealizado uma melhor aceitação e valorização da disciplina no ambiente escolar, por parte de todo corpo docente. Esta busca por valorização e reconhecimento passa, principalmente, por uma transformação no interior da própria Educação Física, que ao longo das últimas décadas tem buscado a especificidade de seu conhecimento e de seus objetivos (BRACHT, 2003). No que diz respeito ao seu papel junto à pedagogia, espera-se que o professor de Educação Física seja um educador que saiba olhar a criança, dar tempo para seus atos, sustentar suas brincadeiras e interagir com elas (LEITE, MEDEIROS, 2014).

Assim como na educação infantil, o primeiro nível do EF foi, durante muito tempo, um campo de trabalho predominantemente feminino, se tornando muitas vezes, conflitante pela presença de outros profissionais como: o professor de Educação Física e o professor de Arte. Como aponta Ayoub (2001), há um "mito", bastante enraizado entre nós, de que para ser professor de criança basta ser mulher e delicada. Isso explica conforme a autora, a presença majoritária de mulheres nos níveis iniciais de ensino e a precariedade da formação profissional.

Por isso são necessárias novas propostas que visem qualificar e orientar a formação generalista. Olhando para a área da Educação Física, esse grupo de profissionais, precisa de uma formação inicial mais ampliada em suas graduações para além da legalidade versus 
legitimidade que, muitas vezes, são vivenciadas quando o professor já está atuando nas escolas. Possivelmente isto daria à generalista uma maior compreensão do trabalho pedagógico em Educação Física.

O conhecimento teórico acerca deste trabalho, poderia minimizar uma má interpretação do papel do especialista na escola. Se em alguns momentos o este profissional é visto como "tapa buraco", como na falta de outro professor ou como um "alívio" para a professora generalista. Tal interpretação se assimilada pelo especialista, pode ser desastroso para a defesa de sua presença na educação de todos os níveis.

Para além das questões relacionadas à formação dos professores, há uma complexa discussão sobre o papel da Educação Física nas séries iniciais do EF. Enquanto um grupo defende que a presença do especialista, outro alega que para a criança o contato com um único professor é melhor (FERNANDES, 2010).

Há também os que defendem que, independentemente ou não da presença do especialista, o importante é que haja uma educação de qualidade, onde as mesmas questões acabam se desdobrando, já que é possível perguntar. Afinal, quem está mais preparado para promover uma Educação Física de qualidade, nesta faixa etária? Seria melhor investir mais na formação do generalista ou garantir a presença do especialista junto à educação infantil e EFAI, assim como nos outros níveis de ensino?

Parece razoável compreender que mesmo uma professora com uma boa formação, teria dificuldade em conduzir o seu trabalho no componente Educação Física com a mesma clareza e competência de um especialista. Acreditamos que um dos riscos da ausência do especialista é que o generalista considere a aula de Educação Física apenas e simplesmente como um momento lúdico e esvaziado de conteúdo e conhecimento específico. Não é novidade que, historicamente, a EF sempre foi vista como uma disciplina menos importante. Como constatou Oliveira (2010), em sua investigação, a Educação Física ainda é vista como um espaço menos rígido do currículo escolar devido a suas características práticas.

Neste sentido, para além de debater sobre a necessidade ou não do especialista, precisamos garantir que os profissionais que atuarão com as crianças nos primeiros anos 


\section{Revista (1) ( \\ Debates Insubmissos}

escolares devem passar por uma formação adequada, que lhes garanta uma postura humana e educadora.

Diversas relações podem ser estabelecidas pensando no bem-estar e no que diz respeito ao ensino e aprendizagem das crianças. Especialista ou generalista são partes inseparáveis do processo de ensino, ambos podem e devem trabalhar de forma interdisciplinar para garantir um ensino de qualidade.

Ser criança é estar sempre em diálogo com o lúdico, estar envolvida no mundo que a cerca, buscando, através dos seus movimentos, conhecer o mundo e apropriar-se dele. A criança precisa estar inserida em uma cultura que valoriza, incentiva e promove a Educação Física, intimamente ligada à cultura corporal de movimento, por isso, cabe a cada professor ter um olhar mais amplo e uma atitude mais integradora. O espaço da Educação Física é propício para que as crianças experimentem diversos movimentos e entrem em contato com os conhecimentos específicos deste componente da cultura. Por isso, segundo Sayão (2002), a brincadeira é eixo central no trabalho pedagógico com as crianças, alertando para o risco de adultos utilizarem-na de maneira funcionalista e defende o "brincar pelo brincar", sem fins pré-definidos.

Esta reflexão nos leva a outra, que diz respeito ao modo como, muitas vezes, tratamos as crianças de maneira "estratigráfica”, como nos alerta Geertz (2008). Ou seja, como se ela fosse composta por camadas diferentes (biológica, psicológica, sociológica, etc.) e cada uma devesse ser pensada e tratada separadamente. Neste caso, a Educação Física seria a área responsável por cuidar do corpo das crianças de maneira bastante específica. Ao contrário, acreditamos, assim como o autor, que todos os seres humanos devem ser percebidos na sua complexidade, integralidade, ou seja, como seres compostos por todos estes aspectos interligados e interdependentes. A Educação Física é uma disciplina que deve tratar pedagogicamente as questões relacionadas a cultura corporal de movimento, de modo a olhar para os alunos de maneira sintética, a partir de sua integralidade.

Quando se fala em Educação Física, fala-se de um compromisso com a totalidade do ser humano, conduzindo-o da alienação para a libertação. Brincar é uma forma prazerosa de 


\section{Revista

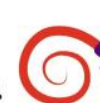 \\ Debates Insubmissos}

descobrir o próprio corpo. É fundamental que o professor tenha consciência das características, necessidades e interesses de seus alunos, para que, a partir desse diagnóstico, consiga elaborar estratégias e propor atividades que favoreçam o alcance de seus objetivos.

Esta discussão se dá de forma mais intensa quando o assunto é a Educação Infantil, mas preocupações semelhantes se estendem ao EFAI. As práticas pedagógicas na Educação Infantil, por exemplo, buscando romper com a lógica formal de ensino, que visa exclusivamente uma "preparação para" o futuro (trabalho), têm apontado modelos diferentes de organização escolar. Nestes novos modelos a presença de um professor especialista é vista como equivocada e desnecessária, uma vez que há a crença de que professores diferentes levam a fragmentação do conhecimento. Sayão (2002) aponta que este modelo de Educação Infantil é uma tentativa de prevenir a "escolarização" centrada no domínio de conteúdos, bem como a antecipação dos mesmos nos primeiros anos da infância. Neste sentido, as Diretrizes Curriculares Nacionais (DCNs) para a Educação Infantil estabelecem uma educação pensada em princípios de integralidade. O que significa um processo de indivisibilidade das dimensões motoras, cognitivas, linguísticas, estéticas, éticas e socioculturais. Estes princípios de integralidade aparecem na transição da Educação Infantil para o EFAI. Neste sentido, o argumento utilizado para defender a presença de um único professor na Educação Infantil, para evitar a fragmentação dos conhecimentos, pode e deve ser questionada quando o assunto é o Ensino Fundamental.

Uma vez que o corpo e o movimento, objetos centrais da disciplina de Educação Física, são fundamentais na apropriação do conhecimento e do mundo, a questão que se coloca é se, de fato, um professor polivalente, sem formação específica, tem a competência necessária para trabalhar com o tema. Podemos questionar, ainda, se o que provoca a fragmentação é a presença de mais do que um professor ou a forma como se desenvolve o trabalho pedagógico. Afinal, segundo Freire (1997), um único professor poderia ser mais desintegrador do que seis ou oito juntos, trabalhando em equipe.

Considerando que a infância é a fase da vida na qual estabelecemos os primeiros contatos com o conhecimento sistematizado e que durante esta etapa a criança se apropria, significa e transforma a realidade a partir da brincadeira (sua atividade principal neste 


\section{noviste

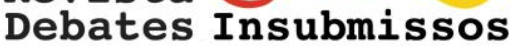

período), compreendemos que o corpo e o movimento assumem centralidade nas relações estabelecidas, tornando-se instrumento de complexificação da realidade.

Diante disso é preciso frisar que este "brincar", no EFAI não é uma atividade desprovida de certa funcionalidade, ainda que um tempo para o "livre brincar" seja necessário. O componente curricular Educação Física possui objetivos e conteúdos específicos. Neste sentido, como afirma Pereira et. al. (2009), o foco de estudo da Educação Física não deve ser qualquer movimento corporal ou atividade física, e sim um movimento com intenções e significados pedagógicos que consigam transcender o "fazer pelo fazer", com vistas à compreensão e reflexão sobre como, por quê, para quê e quando fazer. Ou seja,

[...] brincar com a linguagem corporal significa criar situações nas quais a criança entre em contato com diferentes manifestações da cultura corporal (entendida como as diferentes práticas corporais elaboradas pelos seres humanos ao longo da história, cujos significados foram sendo tecidos nos diversos contextos socioculturais) sobretudo aquelas relacionadas aos jogos e brincadeiras, às ginásticas, às danças e às atividades circenses, sempre tendo em vista a dimensão lúdica como elemento essencial para a ação educativa na infância. Ação que se constrói na relação criança/adulto e criança/criança e que não pode prescindir da orientação do (a) professor (a) [...] (AYOUB, 2001, p.).

Sendo assim, quando passamos a pensar no movimento e no brincar num contexto de ensino-aprendizagem, no qual o contato com o conhecimento sistematizado é fundamental. A formação inicial do professor passa a ser uma condição fundamental que o capacita a lecionar boas aulas.

Ao buscarmos pesquisas anteriores ${ }^{7}$, que tiveram como objetivo analisar a opinião de professores polivalentes sobre se sentirem ou não preparados para assumir as aulas de Educação Física, pudemos concluir que, de maneira geral, a maior parte deles assume não se sentirem aptos a desempenharem tal tarefa. Pereira et al (2009), por exemplo, questionam professores polivalentes de 28 escolas do Município de Santo André (município este que não trabalha com professores especialistas no EFAI), sobre sentirem-se preparados para ministrar aulas de Educação Física, já que não realizaram curso em nível superior que lhes permitisse maior conhecimento das especificidades dessa área.

\footnotetext{
${ }^{7}$ Ver também: Silva Filho e Pereira (2012), no artigo intitulado: "Educação física e professores polivalentes: o caso das escolas públicas municipais de Várzea Grande".
} 


\section{Revista \\ Debates Insubmissos}

Para os autores, a questão de "sentir-se preparado" não se refere apenas à autoconfiança do docente em relação às possíveis dificuldades para ministrar um componente curricular que foge às suas habilidades pedagógicas de formação. Trata-se do questionamento da própria competência para esse exercício, que abarcaria os conhecimentos sobre o desenvolvimento da criança, seus interesses e necessidades, a compreensão da função e importância da Educação Física e, por fim, a mobilização desses conhecimentos em ações pedagógicas durante as aulas.

Em 9 das 28 escolas por eles pesquisadas, as professoras admitiram que deixam os alunos livres ${ }^{8}$ para recrearem. A maioria dos professores restantes sugere que retoma as atividades da própria infância, sem preocupações pedagógicas. Ainda de acordo com esta pesquisa, grande parte dos professores generalistas solicitam um professor especialista e assumem não se sentirem preparados. Um dos professores participantes desta pesquisa afirma que um colega designado apenas como professor de Educação Física tem condições de fazer um trabalho com maior qualidade, uma vez que seu direcionamento seria mais. O mesmo professor também acha que os alunos se comportam de maneira diferente com a mudança de professor.

A falta de preparo, relatada pelos professores generalistas acima, reflete diretamente na relação de ensino-aprendizagem, já que, segundo Ayoub (2001), o corpo aparece de forma secundarizada, visto que é tratado como meio para outros fins. Na maioria dos casos, os professores polivalentes elaboram atividades nas quais o objetivo principal é o desenvolvimento de outras dimensões da criança, que não aquelas preconizadas na área da Educação Física9 ${ }^{9}$. Além disso, Bracht (2003), relata que é comum a utilização das aulas de Educação Física pelos professores polivalentes como compensação ou premiação pelo comportamento dos alunos, como se após realizarem todas as tarefas importantes tivessem a oportunidade de brincar e espairecer.

\footnotetext{
${ }^{8}$ Oliveira (2010), constatou a realidade de aulas sem intervenção pedagógica, onde os alunos ficam à vontade para fazerem o quiserem na aula.

${ }^{9}$ A psicomotricidade ainda pode ser encontrada no argumento de diversos professores polivalentes (inclusive em professores de Educação Física). Segundo Soares et.al. (1992), este modelo, muito famoso na década de 1980, tem como premissa que o corpo e o movimento são fins para o desenvolvimento intelectual e psicológico.
} 


\section{Revista \\ Debates Insubmissos}

Para Betti e Zuliani (2002), a Educação Física, tratada como componente curricular, deve proporcionar aos alunos o acesso à cultura corporal de movimento, transformando-os em cidadãos que tenham condições para usufruir da dança, dos jogos, do esporte, das práticas de aptidão física, sempre em benefício da sua qualidade de vida. Compreende-se que existe uma especificidade para a disciplina de Educação Física, baseada na perspectiva cultural deste componente curricular, nos parece possível afirmar que há, de fato, uma necessidade da presença do professor especialista independentemente do ciclo da educação formal.

\section{METODOLOGIA}

Do ponto de vista metodológico, esta foi uma pesquisa qualitativa que, conforme aponta Minayo (1994), responde a questões muito particulares e que não podem ser simplesmente quantificadas. Para a autora, a pesquisa qualitativa trabalha com o universo de significados, motivos, aspirações, crenças, valores e atitudes produzidos nas relações, nos processos e nos fenômenos sociais.

As técnicas utilizadas foram, além da revisão de literatura, a observação de campo (BRUYNE et al, 1982) e a aplicação de entrevistas semiestruturadas, de acordo com os apontamentos de Triviños (1987). As entrevistas foram baseadas em um roteiro ${ }^{10}$, que permitiu às interlocutoras seguirem espontaneamente sua linha de pensamento e a descrição de suas experiências.

Nessa fase, por se tratar de uma pesquisa bibliográfica, consideramos os estudos de Severino (2007, p. 122) que a descreve como sendo: “[...] aquela que se realiza a partir do registro disponível, decorrente de pesquisas anteriores, em documentos impressos, como

\footnotetext{
10 As perguntas formuladas foram: 1) Há quanto tempo você leciona? 2) Sempre houveram professores especialistas de Educação Física nas escolas em que trabalhou? 3) Se não, há quanto tempo eles passaram a fazer parte do quadro docente da escola? 4) Você nota alguma diferença nas aulas de Educação Física com o passar dos anos? 5) Se sim, você acha que estas diferenças têm relação com a substituição dos professores generalistas pelos especialistas? 6) Na sua opinião, o que é Educação Física Escolar? Quais são os objetivos desta disciplina? 7) O que você pensa sobre as aulas de Educação Física que observa? 8) Qual é a relevância destas aulas para os alunos? 9) O que representa a Educação Física na sua rotina semanal? 10) Quais são as consequências para a sua rotina quando o professor de Educação Física falta? 11) Você gostaria de dizer mais alguma coisa?
} 


\section{Revista \\ Debates Insubmissos}

livros, artigos, teses etc". Esse levantamento bibliográfico auxilia na discussão do problema investigado e também para a construção do referencial teórico que fundamentação algumas considerações.

Em relação ao tratamento das obras que são referência para este trabalho, apoiamo-nos nas diretrizes para leitura, análise e interpretação de textos, de acordo com Severino (2007):

1. Análise textual, que consiste em buscar informações a respeito do autor do texto e verificar o vocabulário, os fatos históricos apresentados pelo texto, com a possibilidade de exibir uma esquematização do mesmo, a fim de propiciar uma visão de conjunto da unidade;

2. Análise temática que procura ouvir o autor e apreender, sem intervir no conteúdo da mensagem apresentada pelo autor, fazendo ao texto uma série de perguntas, sendo que as respostas fornecem o conteúdo da mensagem;

3. Análise interpretativa, em que se busca uma compreensão interpretativa das ideias apresentadas pelo autor. Nesse tipo de análise compreende-se também a crítica, a formulação de um juízo crítico, de tomada de posição;

4. A problematização, que se trata de um tipo de abordagem com vistas ao levantamento dos problemas para a discussão;

5. A quinta e última etapa trata-se da síntese pessoal, da construção lógica de uma redação, de modo a dar condições ao estudioso de progredir no desenvolvimento das ideias do autor.

O referencial teórico deste trabalho está ancorado em autores da Educação e EF. O levantamento bibliográfico ocorreu do mês de maio ao mês de novembro de 2020.

Para a realização da pesquisa de campo, selecionamos uma Escola Estadual do município de Piracicaba - SP. Tal escolha foi pautada, principalmente, na facilidade de acesso, já que um dos pesquisadores é professor de Educação Física nesta escola. Foram selecionadas para as entrevistas 4 professoras generalistas que aceitaram participar e assinaram um termo de consentimento livre e esclarecido de maneira consciente e voluntária, concordando com a divulgação dos resultados mediante a preservação de suas identidades.

Portanto, na elaboração do texto, as trataremos como professora 1, professora 2, professora 3 e professora 4, conforme o quadro abaixo: 
Quadro 1: Participantes da pesquisa

\begin{tabular}{|c|c|l|}
\hline Professora & Tempo de Magistério & Espaço de Atuação \\
\hline P1 & 47 anos & Rede Estadual e Privada \\
\hline P2 & 29 anos & Rede Estadual \\
\hline P3 & 29 anos & $\begin{array}{l}\text { Rede Estadual e } \\
\text { Municipal }\end{array}$ \\
\hline P4 & 23 anos & Rede Estadual \\
\hline
\end{tabular}

O referencial teórico deste trabalho está ancorado em autores da Educação e EF. O levantamento bibliográfico ocorreu do mês de maio ao mês de novembro de 2020.

\section{ANÁLISE DAS ENTREVISTAS}

Por meio das entrevistas buscamos compreender quais são, na visão das professoras de sala, os objetivos e o papel da Educação Física no EFAI. Procuramos analisar se estas professoras consideram o componente curricular Educação Física importante e porquê.

Como forma de preservar a identidade das professoras entrevistadas, optamos por identifica-las através de números de 1 a 4 . Iniciamos com uma breve apresentação de cada uma delas e, na sequência, analisamos as respostas especificamente relacionadas ao objetivo da pesquisa.

A professora 1 leciona há 47 anos, dentre estes, 25 em escolas do Estado e os outros (anteriores) em colégios particulares, mas sempre no EFAI. A professora 2 leciona no EFAI há 29 anos e também é professora de turmas de anos finais em um dos turnos, na disciplina de Língua Portuguesa. A professora 3 trabalha há 29 anos nas escolas do Estado, com o EFAI e há 27 anos, nas escolas da prefeitura, com a Educação Infantil. Por fim, a professora 4 leciona há 23 anos apenas em escolas do Estado com EFAI.

Dentre as 4 professoras apenas a última (P4), talvez por ser a mais jovem e, consequentemente, a que atua há menos tempo, afirma que desde o início de sua carreira existem professores especialistas de Arte e Educação Física trabalhando conjuntamente. As 


\section{Revista \\ Debates Insubmissos}

outras três professoras (P1, P2 e P3), se recordam muito bem do tempo em que não haviam professores de Educação Física em suas escolas.

No início do meu magistério não havia professor de Educação Física. Quem ministrava as aulas era o próprio professor da sala e como eu já leciono há muito tempo, eu era professora de três, quatro séries em dois períodos, e assim fui procurar dar algum exercício de Educação Física, mas era muito pouco, porque era muito cobrado da gente e não tinha tempo suficiente para isso (P1).

Antigamente nós que dávamos todas as disciplinas, as professoras polivalentes. Se me recordo bem, deve ter mais que dez anos com o ciclo básico que começou a ter professor especialista de Educação Física. Nós dávamos mais bola para as crianças, alguma cantiga de roda, tipo pata choca (P3).

Pereira, Nista-Piccolo e Santos (2009), falam sobre a insegurança dos generalistas em ministrarem as aulas de Educação Física. Nós também pudemos notar isto nesta pesquisa, quando ao questioná-las sobre o que faziam nas aulas de Educação Física, elas responderam, por exemplo: professoras 1 e 3: “[...] alguma coisa que dava para gente fazer de acordo com o nosso entendimento, porque nós não somos especialistas em Educação Física (professora 1)”, ou, "fui procurar dar algum exercício de Educação Física, mas era muito pouco (professora 3)". Sem muita confiança sobre o trabalho com a Educação Física, as professoras recorreram a expressões como, "algum exercício, alguma coisa", assim como a P3, ao dizer "alguma cantiga (...) tipo pata choca". Tais afirmações deixam clara a falta de sistematização dos conteúdos e de domínio dos objetivos da disciplina.

Para Darido (2001) e Silva Filho e Pereira (2012), a escolha das atividades das aulas de Educação Física pelos generalistas tendem a ser feitas a partir de suas experiências de infância, dentro ou fora da escola, embora os professores especialistas podem também evidenciar suas ações com traços de suas experiências, mas podem agir de forma mais consciente e planejada, conforme os objetivos da aula programada.

Para além da dificuldade de seleção dos conteúdos, as professoras entrevistadas deixam claro que há um certo descontentamento com a situação, como, por exemplo, quando a P2 fala sobre a cobrança existente em relação a estas aulas. Segundo ela: "Era muito cobrado da gente e não tinha tempo suficiente para isso", sendo essa situação também percebida por Pereira, Nista-Piccolo e Santos (2009), em estudos anteriores. 


\section{Revista \\ Debates Insubmissos}

Desde 2003, as aulas de Educação Física da Educação Básica no estado de São Paulo, devem ser ministradas por licenciados na área (SÃO PAULO, 2003, 2011). Corroborando com o que já foi observado por Pimenta (2000), Nery (2001) e Ferreira e Torres (2013), ao serem questionadas sobre a diferença entre antes e depois da presença do professor de Educação Física, as professoras afirmam que esta mudança foi boa, pois elas não se sentiam preparadas para atuar com o ensino das práticas corporais.

Logo no começo quando havia professor de Educação Física a gente percebia que era muita bola para as crianças, era muita queimada, futebol, trabalhava mais nessa tecla e hoje não, hoje os especialistas procuram fazer um trabalho mais abrangente (P1).

As três professoras (P1, P2 e P3) que vivenciaram a tarefa de dar aulas de Educação Física sem formação específica demonstram perceber uma mudança significativa entre o período que não haviam especialistas e o período posterior.

Hoje eu observo que as aulas de Educação Física são muito importantes porque elas procuram ajudar o aluno a se desenvolver através dos exercícios físicos. Eles usam também (pausa), tem atividade que (pausa), eles usam a memória e isso ajuda muito no nosso trabalho docente (P1).

Quando eu era "professora" (ministrando Educação Física) eu só dava aquelas atividades mais simples. Eu vejo hoje que alguns alunos não gostam de participar e a gente tem que respeitar, ou bolar alguma atividade diferente pra aquele, ao invés de um futebol, fazer uma corda, atividades mais variadas (P3).

As entrevistas também nos confirmaram uma visão funcionalista de Educação Física, como, por exemplo, quando a P1 menciona o fato das atividades auxiliarem na memória e, consequentemente, auxiliarem no trabalho docente em sala. De forma similar a P2 afirma que hoje o trabalho da Educação Física é "complementar e não uma coisa solta”.

Neste sentido, as 3 professoras que vivenciaram a tarefa de lecionar Educação Física sem formação específica demonstram perceber uma mudança significativa entre o período que não haviam especialistas e o período posterior. Ferreira e Torres (2013), confirmam que são unanimes as opiniões das professoras generalistas sobre o fato do professor especialista ser capaz de desenvolver um trabalho com a disciplina de Educação Física melhor do que elas, devido as diferenças em sua formação.

No entanto, podemos perceber que tanto a P1 quanto a P2 ainda possuem uma visão utilitarista da Educação Física, afirmando que aquilo que é feito nestas aulas, pode 


\section{Revista \\ Debates Insubmissos}

"complementar as aulas normais" ou que, "isso ajuda muito o trabalho docente". Ao estabelecer uma diferença entre aula "normal” e Educação Física, fica explícita uma visão, ainda que inconsciente, do modo como as professoras hierarquizam as disciplinas, tratando umas como mais importantes do que outras. Nesta hierarquização elas chegam a mencionar que o que elas fazem é "trabalho docente" como se o que o professor de Educação fizesse não pudesse ser considerado como tal.

Ao questionarmos as professoras sobre quais são as diferenças que elas puderam notar depois da substituição dos professores generalistas pelos especialistas, as participantes P1, P3 e P4, mencionaram as mudanças metodológicas no processo pedagógico, reconhecendo uma limitação na atuação do pedagogo. Isto fica evidente quando a P1 menciona que antes era "muita bola" para as crianças e que, depois, o trabalho ficou mais abrangente. Ou quando a P4 afirma:

Eu observo que hoje as aulas são mais pensadas para as crianças. Antigamente bem no começo, era mais brincadeira, as crianças estavam mais dispostas a brincar e o professor a deixar brincar. Não tinha tanta organização, aquecimento e até mesmo para nós professoras parecia que era hora de lazer (lembrando que ela relata que sempre houve especialista, então ela não está comparando o trabalho do polivalente com o do especialista $\left.{ }^{11}\right)(\mathrm{P} 4)$.

Ao afirmar que as aulas pareciam hora do lazer, a professora apenas confirma o modo como a educação Física foi construída e vista historicamente. Somente nas últimas décadas temos conseguido mudar um pouco esta visão. Conforme apontam diversos autores no campo de estudo, as aulas de Educação Física na escola, podem e devem ser lúdicas, mas isto não significa que não possuem um compromisso pedagógico. Marcellino (2010), também nos alerta que por mais lúdicas que as atividades sejam, elas ainda estão no campo do trabalho escolar e, por isso, não contêm as características necessárias para serem consideradas plenamente como vivências do lazer.

Quando questionadas sobre o que elas entendem por Educação Física e quais sãos seus objetivos, a P1 afirma: "Pra mim, eu acho que a disciplina de Educação Física é a que traz o desenvolvimento da criança, desenvolvimento integral da criança, físico, mente”. Esta opinião

\footnotetext{
${ }^{11}$ Esta afirmação, vinda de uma professora que não se recorda de momentos que não haviam especialistas ministrando aulas de Educação Física no EFAI, nos indica um alerta com relação a que tipo de aula os especialistas ministram nesse ciclo, deixando uma inquietação para trabalhos posteriores.
} 


\section{Revista \\ Debates Insubmissos}

demonstra um conhecimento conceitual sobre a Educação Física, que se evidencia através da perspectiva dualista apresentada pela professora. A dicotomia entre corpo e mente, é um tipo de abordagem da área e que, apesar de retratar tendências anteriores da disciplina, é encontrada até hoje nos processos de ensino de todo o país.

Esta perspectiva fica evidente, também, quando a P2 afirma que a Educação Física desenvolve algumas capacidades no aluno que em sala não seria possível. Mas ao ser questionada sobre quais seriam estas capacidades ela diz que não saberia distinguir quais são, apenas sabe que elas, por serem generalistas, não teriam condições de trabalhar. A questão que se coloca aqui não diz respeito às diferenças no modo de trabalhar entre professoras generalistas e especialistas uma vez que as condições de trabalho estão totalmente relacionadas a formação diferenciada de cada uma. O que parece significativo nesta questão é a o que a professora está se referindo ao usar o termo "capacidades", já que nos parece, em sua fala, totalmente atrelado as questões físicas.

Já a P3, ao abordar o assunto, parece ter mais conhecimento sobre a abordagem cultural de Educação Física, conseguindo perceber, por exemplo, que a disciplina "não é para preparar um atleta". Acrescenta ainda que, os especialistas podem desenvolver alguns valores como: "colaboração, participação, regras" assumindo achar "muito importante as regras".

A P3 ainda menciona a relação entre Educação Física e competição, afirmando que acredita na importância de se trabalhar: "atividades com jogos, tipo campeonato, ou gincana, porque o aluno precisa aprender a ganhar e a perder, na Educação Física ele está brincando e aprendendo regra, eu acho muito importante". Há duas questões a serem analisadas nesta fala da professora. A primeira diz respeito, mais uma vez, a visão funcionalista da disciplina, que fica clara ao afirmar que a criança aprende "outras" coisas enquanto brinca. A segunda, intimamente relacionada a primeira, diz respeito ao fato da professora desconsiderar a importância de aprender sobre o próprio jogo ou brincadeira, como se o que realmente importasse não fosse o conteúdo, em si, mas os valores a ele atrelados. Esta opinião, muito comum, demonstra a falta de conhecimento sobre a especificidade da Educação Física e de seus conteúdos. Não pensamos que estes valores não possam ser aprendidos ou discutidos nas aulas de Educação Física, mas sabemos que este não deve ser o objetivo central das aulas. 


\section{Revista \\ Debates Insubmissos}

A P4 corrobora com as afirmações da P3, principalmente no que se refere a questão dos valores atrelados aos conteúdos. Ela afirma: "Não tenho muita clareza disso (...), mas eu penso que trabalha a interatividade, respeito, valores, não consigo pensar em algo que tenha haver com condicionamento físico". Se, por um lado, ela finaliza sua resposta, refutando uma perspectiva higienista da disciplina, vinculada ao treinamento e preparo dos corpos, ela "tropeça", do mesmo modo que a P3, na falta de conhecimento sobre a especificidade da disciplina de Educação Física, como se suas aulas servissem, não para ensinar sobre os conteúdos em si, mas sobre os valores e coisas secundárias a eles vinculados.

Se, por um lado, elas ainda possuem uma visão funcionalista sobre a disciplina, insistindo sobre a importância de valores como "ganhar" e "perder", por outro lado, as professoras P3 e P4, demonstram um entendimento de Educação Física que se aproximam mais da perspectiva atual desta disciplina na escola, ou seja, um distanciamento da esportivização e do treinamento.

Não é para preparar um atleta. É a parte da colaboração, da participação, de regras, eu acho muito importante as regras. Fazer atividades com jogos, tipo campeonato, ou aquela gincana, porque o aluno precisa aprender a ganhar e a perder. Na Educação Física ele está brincando e aprendendo regra, eu acho muito importante (P3).

Não tenho muita clareza disso não, acho que nunca parei para pensar sobre, mas eu penso que trabalha a interatividade, respeito, eu penso muito nos valores, não consigo pensar em algo que tenha haver com condicionamento físico, não creio que seja isso, creio que o propósito seja a interação, respeito, outros valores, que não esse (atividade física como exercício) (P4).

Ao serem questionadas sobre as aulas de Educação Física, a opinião dos alunos foram assim respondidas:

[...] eles gostam das atividades que são propostas [...] o que eu percebo é que eles pensam é na alegria de participar dessa aula [...] (P1).

[...] Ah! que eles vão correr extravasar, gritar (risos), eles pensam isso. Que é uma atividade mais livre, que eles vão correr, vão brincar. Eles não percebem que é uma disciplina, que eles vão aprender, eles vão pra lá pra brincar (P3).

[...] Tem aquele que a Educação Física é apenas lazer, não toma como aula, e tem aquele que vai sair, ele vai desenvolver uma atividade diferente, ele vai aproveitar isso, mesmo fora da aula, através de dança, [...] de esporte, [...] eu creio que a Educação Física também vai dar esse norte pra ele se desenvolver, nessa parte de prática esportiva, além do prazer ( $\mathrm{P} 2)$. 


\section{Revista \\ Debates Insubmissos}

As professoras entendem que os alunos relacionam a disciplina com um tempo mais livre, de diversão. Para os alunos, os objetivos da disciplina e os conteúdos em si, não são relevantes. Talvez eles sequer tenham clareza dos objetivos deste componente curricular, mas gostam muito do modo como ele é tratado na escola. De maneira geral, os alunos valorizam a Educação Física porque é um momento no qual estão fora da sala de aula e podem se sentir mais livres. A P1 ainda ressalta a alegria dos alunos quando chega a hora da Educação Física e, por sua vez, a tristeza quando o professor falta ou por algum outro motivo eles descobrem que não terão aula naquele dia.

O comentário da professora 2, esboça uma questão relevante, que diz respeito ao modo como a Educação Física promove a ampliação do repertório corporal dos alunos. Este objetivo é fundamental para autores da área que compactuam com um viés cultural, como, por exemplo, Daolio (1998) e Betti (1994), que falam sobre como a ampliação deste repertório da cultura corporal de movimento promove a autonomia dos alunos para que estes tenham condições de buscar estas práticas fora da escola.

Ainda em relação a esta mesma pergunta, a resposta da professora 4 é bastante significativa:

Talvez, porque eu dou aula para as séries iniciais, para as crianças bem pequenas, eu acho que eles pensam que é uma continuação do parquinho da escola infantil, que eles vão sair para brincar, eles têm isso, que eles vão brincar. E eu acho que o professor da sala, a gente não desdiz isso né, a gente acaba confirmando isso, com as nossas atitudes. Tem alguns que reforçam, que é mesmo uma hora de lazer, que é mesmo a hora do "ufa", alívio da sala de aula, eu acho que é isso (P4).

A professora reconhece que o modo como elas, generalistas, tratam a "hora da educação Física" contribui com a visão equivocada que as crianças desenvolvem sobre esta disciplina. Em um movimento de autocrítica, ela destaca que este comportamento dos alunos, não é revisto e até mesmo é reforçado pelas professoras generalistas. Sabemos que muitas professoras de sala utilizam o apreço dos alunos pela aula de Educação Física para ameaçalos, negociando o bom comportamento deles, às custas de serem castigados ficando sem a aula tão esperada. Ferreira e Torres (2013) ouviram das professoras generalistas, de forma unânime, que a disciplina de Educação Física é muito importante para os alunos. 


\section{Revista \\ Debates Insubmissos}

Perguntamos as professoras, quais as consequências para a rotina delas, quando o professor de Educação Física falta. As respostas ajudaram a esclarecer também a pergunta anterior.

[...] quando o professor falta, por algum motivo justo, eles reclamam porque eles querem as aulas de Educação Física. [...] eles ficam um pouco agitados, irritados porque não teve aula de educação física, mas como eu sempre tenho muito trabalho para ser feito e muita atividade para serem dadas, eu converso com eles e explico o porquê que o professor não pode vir e eu consigo trabalhar normalmente (P1).

Esta resposta apenas confirma o apreço dos alunos pelas aulas de Educação Física e o quanto a falta dela altera o ânimo das turmas. A resposta também reforça que o pareço pelas aulas se deve não a importância de seus conteúdos, mas o sentimento de prazer e liberdade a ela atrelados.

Diferentemente da P1, a P2, afirma que não consegue controlar o descontentamento dos alunos, nas ausências do professor de Educação Física. Ela afirma que falta desta aula causa um impacto expressivo em sua rotina, ideia reforçada e compartilhada pela P4.

[...] uma tristeza (risos), uma tristeza, os alunos reclamam, porque eles querem a aula que é uma coisa prazerosa, gostosa, diferente e passa rápido, né? Passa rápido, então ficam tumultuados e mesmo quando a gente tenta fazer alguma coisa, não alcança, não resolve esse problema (P2).

[...] eu fico apavorada, porque eu já contava com aquela brecha para eu pensar nas atividades, que eu iria preparar para as últimas aulas. É um sério problema (P4).

A P3 deixa bastante explicitado o descontentamento gerado pela falta do professor de Educação Física nos alunos, mas a P4 revela mais o próprio descontentamento em perder aquela hora que ficaria livre. De todo modo é notório o impacto causado na rotina da escola.

Sexta-feira o professor de Educação Física faltar é uma maravilha (o professor de
Educação Física tinha faltado duas sextas-feiras seguidas). Então, eu estou sendo
sincera. Não vai mudar nada, porque eu não vou leva-los para a quadra, eu vou
pegar e bolar uma outra atividade, que tem lá várias, então foge um pouco da rotina,
do planejado, mas a gente vê outra atividade, encaixa, eles também ficam
decepcionados, você tem que explicar que o professor teve alguma dificuldade,
assim como eventualmente a professora da sala também vai ter que faltar. Mas há
uma decepção de ambas as partes, dos alunos e da professora, aí a professora rebola
e manda ver(risos) (P3).

Para finalizar as entrevistas, perguntamos se elas gostariam de falar mais alguma coisa sobre o assunto, de maneira geral. A Professora 1, apesar de afirmar que a entrevista já tinha esgotado o assunto, fez questão de reforçar o que já havia dito anteriormente, afirmando que, 


\section{Revista \\ Debates Insubmissos}

para ela, a Educação Física está no currículo porque ajuda a "desenvolver" os alunos e isso ajuda na rotina delas, em sala de aula.

Eu só queria dizer que é muito importante essas aulas no nosso currículo escolar porque isso tá ajudando muito os nossos alunos, eles gostam, eles se desenvolvem e isso ajuda muito na nossa rotina (P1).

Já a P2 salienta a importância de que seja o especialista a trabalhar com a Educação Física e reforça sua ideia, afirmando o mesmo com relação a Arte.

Isso foi uma das melhores coisas que aconteceu para nós, tanto a Educação Física quando a Educação Artística, [...] ter dois especialistas da área para trabalhar com essas crianças [...] ficou uma coisa boa (P2).

Vale lembrar que esta professora é a que demonstrou a visão mais aproximada da perspectiva cultural de Educação Física. Neste sentido, ao afirmar que a presença do especialista é "um ponto positivo", ela parece compreender melhor a importância de alguém com formação específica para que a especificidade da disciplina seja garantida.

A P3 respondeu finalizou a conversa fazendo uma análise comparativa entre a Educação Física que ela observa hoje, como professora, e a que ela teve em sua escolarização. Em sua perspectiva, as aulas de hoje tendem a estimular os alunos a conhecerem de forma mais agradável as práticas corporais.

Eu espero que sirva, porque eu acho que o professor de Educação Física deve ser valorizado. E se me pegar como experiência, será que eu não fui estimulada, lá na minha quinta série, para eu gostar de exercício físico? Pode ser que se eu tivesse sido estimulada, hoje eu gostasse de exercício. Porque eu sinto necessidade de fazer exercício, a idade vem chegando, as gordurinhas, e eu vou na academia e não sinto prazer (P3).

Neste sentido, apesar de sua fala esboçar uma visão de educação física conectada com uma formação para o futuro (pós-escolar), essa visão é, ainda, muito reduzida à perspectiva do exercício e não das práticas corporais como conteúdo da cultura de movimento.

A P4 também faz essa análise comparando seu histórico como aluna com sua experiência atual com as práticas corporais.

Só nessa questão aí, a escola evoluiu bastante, hoje não tem mais essa atitude de tolher uma aluna, de constrange-lo né? Isso já é um grande passo, porque outras crianças, não tem medo da Educação Física igual eu tive a vida inteira né? Até de academia, porque eu achava que já iria entrar para dar errado, não queria fazer dança nada, porque eu sou uma pata. [...] eu acho que eu era só uma criança, que não 


\section{Revista \\ Debates Insubmissos}

conhecia aquele esporte, que era outra realidade. A professora que era a parte detentora do saber, devia perceber que eu não sabia, mas não, ela chutava o traseiro, não de uma só, de várias, para ela aquilo era uma brincadeira, embora ela tivesse com tom sério, mas para mim nunca foi brincadeira, eu só tinha dez nas outras matérias (P4).

A fala da professora, que é também um desabafo sobre sua época de aula, nos alerta para uma questão fundamental e ainda muito presente nas escolas: a segregação dos alunos por habilidade. Ainda que hoje estas questões estejam minimizadas, é muito comum encontrarmos professores que prezam pela aptidão e habilidade motora dos alunos, excluindo aqueles que "não levam jeito". Este tipo de aula, excludente, produz experiências negativas que marcam a vida de uma pessoa até a idade adulta. A fala da professora nos alerta para o fato de que a maturidade intelectual da área e a formação inicial dos professores pode ser um divisor de águas entre abordagens mais reducionistas (desenvolvimento motor, treinamento) e aquelas com um olhar mais ampliado e complexo (perspectivas culturais).

\section{CONSIDERAÇÕES FINAIS}

As entrevistadas realizadas evidenciaram que as professoras de sala, ou generalistas, valorizam a presença do professor especialista. Em seus discursos podemos perceber resquícios de uma visão utilitarista, segundo a qual a Educação Física deve servir como complemento ou disciplina auxiliar do trabalho pedagógico realizado em sala. Percebemos, ainda, uma compreensão de Educação Física como "aula livre" ou momento para diversão e lazer. Visão esta, muito comum e enraizada na história desta disciplina.

A entrevista anuncia que as professoras generalistas "sabem que não sabem" o que é Educação Física e reconhecem que há um tipo de conhecimento que elas não dão conta. Elas assumem que isto é positivo e que as crianças podem se apropriar desses conhecimentos. Apesar de reconhecerem que não sabem fazer o trabalho do especialista porque este é detentor de um conhecimento específico, elas deixam escapar uma visão hierarquizante segundo a qual a Educação Física é menos importante do que o trabalho que realizam em sala.

Fica evidente, portanto, que elas possuem uma visão de que a Educação Física e as outras disciplinas se completam, mas não possuem o mesmo status. Essa relação dicotômica, 
esboçada pelas professoras fica ainda mais evidente quando elas comentam sobre os dias em que o professor de Educação Física falta aula. Se, por um lado, elas não compreendem a Educação Física como um componente curricular com a mesma importância de outros, por outro lado, a presença do professor na escola é valorizada porque possibilita a elas uma hora no dia longe da sala de aula (longe dos alunos). A partir das respostas dadas a esta questão é possível estabelecer os parâmetros de uma relação que chamamos de "amor e ódio" das professoras generalistas em relação aos professores especialistas.

\section{REFERÊNCIAS}

AYOUB, Eliana. Reflexões sobre a educação física na educação infantil. Revista Paulista de Educação Física, São Paulo, Supl. 4, p. 53-60, 2001.

BETTI, Mauro. Valores e finalidades na educação física escolar: uma concepção sistêmica. Santa Maria, RS: Revista Brasileira de Ciências do Esporte, vol. 16, n. 1, pp. 14-21, 1994.

BRACHT, Valter. Pesquisa em ação: educação física na escola. Ijuí, RS: Unijuí, 2003. BRUYNE et al. Dinâmica da pesquisa em ciências sociais. Rio de Janeiro: Francisco Alves; 1982.

CHARTIER, Anne Marie. A formação de professores na França e a criação dos Institutos Universitários de Formação de Mestres. In: WARDE, Miriam Jorge (org.). Novas políticas educacionais: Críticas e perspectivas. São Paulo: PUC, 1998.

DAOLIO, Jocimar. Da cultura do corpo. Campinas: Papirus; 1998.

DARIDO, Suraya Cristina. Educação Física de $1^{\mathrm{a}}$ a $4^{\mathrm{a}}$ série: quadro atual e as implicações para a formação profissional em Educação Física. Revista Paulista de Educação Física, São Paulo, supl. 4, p. 61-72, 2001.

FERNANDES Anoel. A política educacional da rede pública estadual paulista e a presença do professor de educação física nas séries iniciais do ensino fundamental. Conexões, Campinas, v. 8, n. 1, p. 110-118, jan./abr. 2010.

GEERTZ, Clifford. A interpretação das culturas. Rio de Janeiro: LTC, 2008.

GUIRRA, Frederico Jorge Saad; PRODÓCIMO, Elaine. Trabalho corporal na educação infantil: afinal, quem deve realizá-lo? Motriz: rev. educ. fis., vol.16, n.3, jul./set., 2010.

LEITE, Ana Maria; MEDEIROS, Maria Lúcia. Brincar na escola: caminhos e escolhas. Cadernos CENPEC. São Paulo - v.4, n.1, jun. 2014, p.142-163.

MEDINA, João Paulo Subirá. A educação física cuida do corpo ...e mente. Campinas, Papirus, 1983. 
MINAYO, Maria Cecília Sousa; SANCHES, Odécio. Quantitativo-Qualitativo: Oposição ou Complementaridade? Cad. Saúde Públ: Rio de Janeiro, 9 (3), p. 239-262, jul./set., 1993.

NERY, Cleide. A prática pedagógica da Educação Física nas séries iniciais do Ensino Fundamental e suas relações com o perfil de formação de professores. 2001. $142 \mathrm{fls}$. Dissertação (Mestrado), Faculdade de Ciências e Letras, Unesp, Araraquara, 2001.

OLIVEIRA, Rogério Cruz de. Na "periferia" da quadra - Educação Física, cultura e sociabilidade na escola. 2010. 201 s. Tese (Doutorado). Departamento de Educação Física, Unicamp, Campinas, 2010.

PEREIRA, Raquel Stoilov; PICCOLO, Vilma Leni Nista; SANTOS, Sheila Aparecida Perreira. A educação física nas séries da fase inicial do ensino fundamental: olhar do professor polivalente. R. da Educação Física/UEM. Maringá, v. 20, n. 3, p. 343-352, 2009.

PIMENTA, Maria. A concepção das diretoras e coordenadoras pedagógicas a respeito da educação física de 1a. a 4a. série. Rio Claro, Departamento de Educação, Instituto de Biociências, UNESP, 2000.

SÃO PAULO. Secretaria do Estado da Educação. Resolução SE No 81, de 16-12-2011. Disponível em: http://siau.edunet.sp.gov.br/ItemLise/arquivos/81_11.HTM. Acesso em: 01 de set. de 2017.

SÃO PAULO. Secretaria do Estado da Educação. Coordenadoria de Estudos e Normas Pedagógicas. Proposta Curricular de Educação Física, 2003.

SAYÃO, Deborah Thomé. Infância, Educação Física e Educação Infantil. In: Síntese da Qualificação da Educação Infantil. Secretaria Municipal de Educação/SME. Prefeitura Municipal de Florianópolis/PMF. Florianópolis, 2000.

SEVERINO, Antônio Joaquim. Metodologia do Trabalho Científico. São Paulo: Editora Cortez, 2007.

SILVA FILHO, Manoel Francelino da; PEREIRA, Raquel Stoilov. Educação física e professores polivalentes: o caso das escolas públicas municipais de várzea grande. Revista Mackenzie de Educação Física e Esporte, v. 11, n. 2, 2012, p. 161-187.

SOARES, C. L. et al. Metodologia do Ensino de Educação Física. São Paulo: Cortez, 1992. THIOLLENT, Michel. Crítica metodológica, investigação social e enquete operária. São Paulo: Polis, 1987.

TRIVIÑOS, Augusto Nivaldo Silva. Introdução à pesquisa qualitativa em ciências sociais: a pesquisa qualitativa em educação. São Paulo: Atlas, 1987.

Recebido: 23/03/2021

Aprovado: 04/12/2021 